Supporting Information for:

\title{
Structural and Vibrational Properties of CuPc/Ag(111) Ultrathin Films
}

\author{
Sebastian Thussing and Peter Jakob* \\ Fachbereich Physik und Wissenschaftliches Zentrum für Materialwissenschaften der \\ Philipps-Universität Marburg, Renthof 5, D-35032 Marburg, Germany \\ E-mail: peter.jakob@physik.uni-marburg.de
}



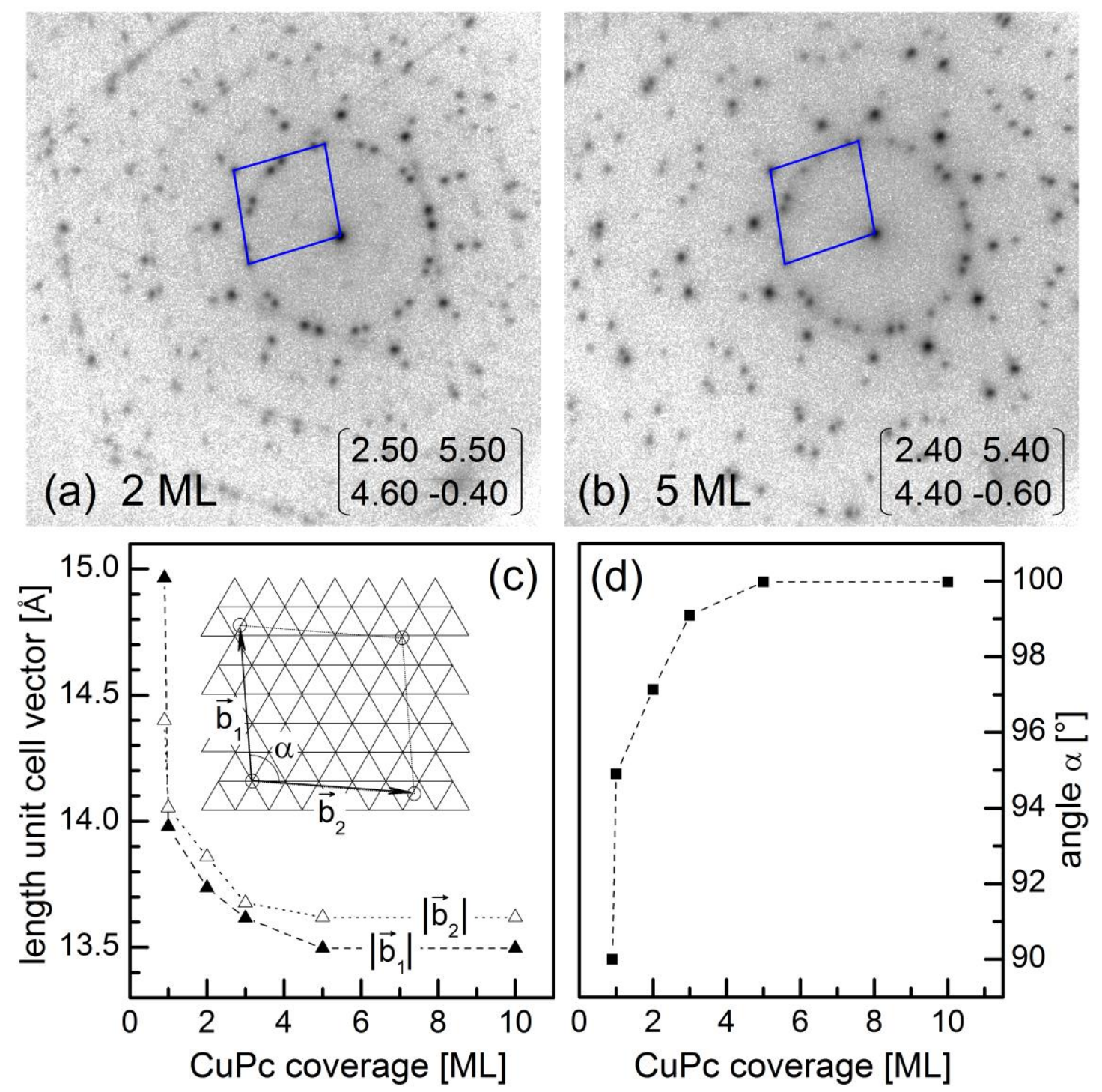

Figure S1: SPA-LEED patterns, including the respective matrix description of the superstructures of $2 \mathrm{MLCuPc}(\mathrm{a})$, and $5 \mathrm{MLCuPc}(\mathrm{b})$, deposited on $\mathrm{Ag}(111)$ at $300 \mathrm{~K}$. The SPA-LEED measurements have been performed at $77 \mathrm{~K}$. In panel (c) the lengths of the unit cell vectors $\left|\vec{b}_{1}\right|$ and $\left|\vec{b}_{2}\right|$ (as defined in the figure) of the CuPc superstructure are shown for various CuPc coverages, starting with the commensurate c-phase (0.9 ML), up to $10 \mathrm{ML}$ CuPc films. The inset represents the unit cell of the CuPc bilayer with respect to the Ag lattice. (d) depicts the angle $\alpha$ between the unit cell vectors $\vec{b}_{1}$ and $\vec{b}_{2}$. 